\title{
Chromium and cadmium adsorption on radiation-grafted polypropylene copolymers: regeneration, kinetics, and continuous fixed bed column studies
}

\author{
Girlie Eunice P. Lopez ${ }^{1}$ (D . Jordan F. Madrid ${ }^{1}$ Lucille V. Abad'
}

Received: 27 September 2019 / Accepted: 3 February 2020 / Published online: 13 February 2020

(c) Springer Nature Switzerland AG 2020

\begin{abstract}
Metal ion adsorbents bearing amino and iminodiacetic groups were synthesized via radiation-induced graft polymerization of emulsified glycidyl methacrylate monomer from polypropylene non-woven fabric followed by subsequent reaction of the epoxide functional groups with ethylenediamine or iminodiacetic acid. The resulting amino- and iminodiacetic-type adsorbents exhibited excellent $\mathrm{Cr}(\mathrm{VI})$ and $\mathrm{Cd}(\mathrm{II})$ adsorption performance, respectively, based on the results of batch and column adsorption experiments. The $\mathrm{Cr}(\mathrm{VI})$ ions bound on the amino-type adsorbent were desorbed with $2 \mathrm{M}$ $\mathrm{NaOH}$ solution, while the bound $\mathrm{Cd}(\mathrm{II})$ ions were effectively stripped off from the iminodiacetic-type adsorbent by using organic acids, such as citric, acetic and oxalic acid. Both adsorbents showed more than $94 \%$ adsorption efficiency after five consecutive adsorption-desorption cycles. The adsorption dynamics of the metal ions to the synthesized grafted adsorbents obeys pseudo-second order kinetics. The radiation-grafted adsorbents exhibited comparable, if not better performance than commercially available ion-exchange resins. Continuous fixed bed column adsorption was performed, and the breakthrough curves were plotted at varying feed solution flow rate. The column-packed amino-type adsorbent can treat more than $4000 \mathrm{BV}\left(>1500 \mathrm{~mL}\right.$ ) of $3 \mathrm{ppm} \mathrm{Cr}(\mathrm{Vl})$ solution at $155 \mathrm{BV} \mathrm{hr}^{-1}$ flow rate before the breakthrough. Lastly, the amino-type adsorbent was successfully applied in the treatment of actual tannery wastewater, with the resulting effluents meeting the national standards.
\end{abstract}

Keywords Amino-type adsorbent · Iminodiacetic-type adsorbent · Desorption · Column adsorption · Radiation-induced grafting $\cdot$ Fibrous adsorbent

\section{Introduction}

Chromium ( $\mathrm{Cr}$ ) and cadmium ( $\mathrm{Cd}$ ) have been used extensively in chemical processes of different industries, mostly in the production of leather, paint pigments, batteries, coatings, and plating. As a result, immense amounts of heavy metal contaminated wastewaters are generated and have caused significant concerns in human health and the environment. These metals have high water solubility and could be easily absorbed by living organisms thus; it is imperative to remove or minimize their presence in industrial effluents using processes such as biological methods, chemical precipitation, ion exchange, or adsorption. Among these, adsorption remains one of the most attractive techniques in the remediation of metal ions due to its simplicity, high recovery, efficiency, and industrial applicability [1, 2].

Several materials were studied such as alumina, synthetic zeolites, industrial or agricultural by-products, natural fibers and many more for heavy metal removal or recovery [3-5]. Some have been produced commercially, like activated carbon and ion-exchange resins. However,

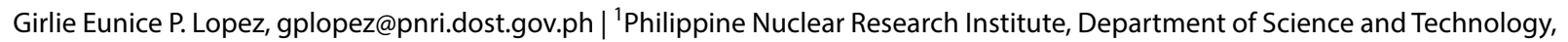
Commonwealth Ave., Diliman, Quezon City 1101, Philippines. 
these commercially available adsorbents typically operate at a low flow rate of $0.5-8 \mathrm{BV} / \mathrm{h}$. Economically speaking, an adsorbent that can sustain a higher flow rate is more attractive because it could potentially reduce the operating cost [6]. Hence, the development of effective, low-cost adsorbents applicable at high flow rates is the main focus of researches nowadays.

While a significant number of publications utilize locally available natural fibers to address the cost and sustainability issue, such materials are known to have undesirable characteristics particularly high moisture absorption, inconsistent size of fiber diameters, and lower mechanical strength compared to synthetic fibers [7]. Treatments like blending with synthetic fibers could improve these drawbacks, but the cost could also increase in a large-scale term. Alternatively, synthetic fibrous material, like polypropylene (PP), have been of interest. Aside from it is low in cost, it has a large surface area, high adsorption rates and capacity than typical spherical resin adsorbents and has been shown to have a high tolerance for higher flow rates $[6,8,9]$.

Glycidyl methacrylate (GMA) is used widely in adsorbent synthesis. The presence of epoxide group in GMA allows facile incorporation of chelating or ion-exchanging functional groups on the surface such as thiol, phosphate, sulfonic acid, hydroxyl, amide, and amino. These groups can serve as sites for adsorption of metal ions through electrostatic interactions, ion exchange, or a combination of both [10]. Several studies were reported on the preparation of functional GMA based fibrous adsorbents for the removal of heavy metals. Kavaklı et al. [11] prepared GMA modified PE/PP chelating fabric for the adsorption of phosphate. Barsbay et al. [12] worked on the development of porous cellulosic adsorbent modified with PGMA followed by reaction with iminodiacetic acid for the removal of $\mathrm{Cd}(\mathrm{II}), \mathrm{Pb}(\mathrm{II})$ and $\mathrm{Cu}(\mathrm{II})$. They reported adsorption capacities values of $53.4 \mathrm{mg} \mathrm{Cd}(\mathrm{II}) / \mathrm{g}$ polymer, $52.0 \mathrm{mg} \mathrm{Pb}(\mathrm{II}) / \mathrm{g}$ polymer, and $69.6 \mathrm{mg} \mathrm{Cu}(\mathrm{II}) / \mathrm{g}$. Boron selective adsorbent was also prepared by Ting and Nasef (2017) using PE/PP fibers. Sekine et al. (2010) used non-woven cotton fabric adsorbent, which showed high adsorption capacity in the removal of $\mathrm{Hg}$ ions. Although some studies on the adsorption of $\mathrm{Cr}(\mathrm{VI})$ using polyGMA grafted fibrous adsorbents $[11,13]$ were already carried out, the use of PP as trunk material together with the evaluation of its continuous adsorption performance using both synthetic and actual wastewaters have not yet been reported. Thus, this work aims to report the performance of radiation-grafted PP adsorbents against $\mathrm{Cr}(\mathrm{VI})$ and $\mathrm{Cd}(\mathrm{II})$ ions using fixed bed column adsorption, and its application against actual tannery wastewater samples.

GMA-based fibrous adsorbents could be conveniently prepared using radiation-induced graft polymerization.
This technique allows the development of materials that cannot be synthesized using conventional grafting methods. The synthesis of PP non-woven fabric adsorbent using electron beam graft polymerization of GMA on PP has been previously investigated by the authors. The parameters for grafting GMA on PP was studied and determined using the full-factorial design. Using the optimum parameters, a polypropylene-graft-poly(glycidyl methacrylate) (PP-g-PGMA) with $150 \%$ degree of grafting (Dg), which was found to be sufficient for adsorbent applications, was produced. Post-grafting reactions were performed by functionalization of PP-g-PGMA with ethylenediamine and iminodiacetic acid. These covalently bonded chemical groups, serve as active sites in the removal of $\mathrm{Cr}(\mathrm{VI}), \mathrm{Cd}(\mathrm{II})$ and $\mathrm{Pb}$ (II) in aqueous solutions [14].

In the present study, the repeated use and regeneration of amino- and iminodiacetic-type adsorbents were evaluated. The adsorption kinetics of the synthesized adsorbents were assessed and compared to commercial ionexchange resin products. Continuous fixed bed column adsorption of $\mathrm{Cr}(\mathrm{VI})$ and $\mathrm{Cd}(\mathrm{II})$ solutions at different flow rates was also carried out. Lastly, the performance of the amino-type adsorbent in the removal of $\mathrm{Cr}$ ions was determined using actual wastewater collected from a leather tannery in the Philippines.

\section{Materials and methods}

\subsection{Materials}

The polypropylene nonwoven fabric trunk polymer was purchased from Agriculture \& Supplies Corp. (Philippines). The glycidyl methacrylate monomer (GMA, $\geq 99.7 \%$, Aldrich), polyoxyethylene sorbitan monolaurate (Tween 20) surfactant, ethylenediamine (EDA, > 99\%, Sigma-Aldrich), iminodiacetic acid (IDA, > 98\%, Aldrich), potassium dichromate $\left(\mathrm{K}_{2} \mathrm{Cr}_{2} \mathrm{O}_{7}, \geq 99.9 \%\right.$, Vetec), sodium hydroxide ( $\mathrm{NaOH}, \geq 99.9 \%$, Vetec), ammonium acetate $\left(\mathrm{NH}_{4} \mathrm{OAc}, \geq 98 \%\right.$, Aldrich), oxalic acid (Labscan), citric acid (Unichem), acetic acid (Macron Fine Chemicals), isopropanol (IPA, > 99.8\%, RCI Labscan), and methanol (> 99.9\%, $\mathrm{RCI}$ Labscan) were all analytical grade reagents and used as received.

\subsection{Preparation of amino- and iminodiacetic-type adsorbents}

The procedure for irradiation and synthesis of the grafted adsorbent was described in our previous study [14]. Briefly, the PP samples, irradiated using electron beam at $40 \mathrm{kGy}$, were reacted with the monomer emulsion containing 5\% (w/w) GMA, and Tween 20 at 5:1 (w/w) GMA-Tween 20 ratio 
for $3.5 \mathrm{~h}$ at $40^{\circ} \mathrm{C}$. After grafting, the samples were washed thoroughly with methanol then dried in vacuo overnight at $40^{\circ} \mathrm{C}$. The PP-g-PGMA copolymers with approximately $150 \% \mathrm{Dg}$ were used in the subsequent functionalization steps to produce the amino- and iminodiacetic acid-type adsorbents (Fig. 1).

In the preparation of the amino-type adsorbent, PP-gPGMA was added to a $50 \%$ (w/w) EDA/isopropanol solution at $60^{\circ} \mathrm{C}$. After 30 minutes, the aminated sample was removed from the reaction solution, repeatedly washed with methanol then dried in vacuo at $40^{\circ} \mathrm{C}$. The iminodiacetic acid functional group was incorporated to the PP-g-PGMA copolymer through its reaction with a $0.4 \mathrm{M}$ IDA solution in $50 \%(\mathrm{w} / \mathrm{w})$ isopropanol/water solution. The reaction was performed at $80^{\circ} \mathrm{C}$ for $24 \mathrm{~h}$. The iminodiacetic acid functionalized PP-g-PGMA was washed by stirring in water for $4 \mathrm{~h}$ at room temperature, then with methanol prior to oven drying in vacuo at $40^{\circ} \mathrm{C}$.

\subsection{Desorption studies}

The amino- and iminodiacetic acid-functionalized PP-gPGMA having 3.0 and $1.2 \mathrm{mmol} / \mathrm{g}$-adsorbent functional group densities, respectively, were used in the desorption studies. To prepare the metal ion-loaded adsorbents, a weighed piece of the amino- or iminodiacetic acid-type adsorbent was stirred in $50-\mathrm{mL}$ of $10 \mathrm{ppm}$ metal ion solution. The $\mathrm{Cr}(\mathrm{VI})$ and $\mathrm{Cd}(\mathrm{II})$ solutions were adjusted to $\mathrm{pH} 4$ and 6 , respectively, using $0.1 \mathrm{M} \mathrm{NaOH}$ or $0.1 \mathrm{M} \mathrm{HCl}$ before adsorption [14]. After $24 \mathrm{~h}$ contact time, the sample was removed and washed thoroughly with water to remove any unbound $\mathrm{Cr}(\mathrm{VI})$ and $\mathrm{Cd}(\mathrm{II})$ ions.

The desorption properties of different organic and inorganic solutions were studied using the prepared metal ion-loaded adsorbents. The desorption of $\mathrm{Cd}$ (II) ions bound on the iminodiacetic acid-functionalized PPg-PGMA was evaluated using $0.1 \mathrm{M}$ oxalic acid, $0.1 \mathrm{M}$ citric acid and $0.1 \mathrm{M}$ acetic acid solutions, while $1 \mathrm{M} \mathrm{NH} 4 \mathrm{OAc}$ and different concentrations of $\mathrm{NaOH}(1 \mathrm{M}, 1.5 \mathrm{M}, 2 \mathrm{M})$ solutions were tested in the removal of bound $\mathrm{Cr}(\mathrm{VI})$ ions from the amino- functionalized PP-g-PGMA. The metal ion-loaded adsorbent was immersed with continuous stirring in a 50 $\mathrm{mL}$ desorbing solution for $24 \mathrm{~h}$. Aliquots before and after the adsorption and desorption procedures were collected, filtered and analyzed using Inductively Coupled PlasmaOptical Emission Spectrophotometry (ICP-OES) for $\mathrm{Cr}$ and $\mathrm{Cd}$ content. The percent desorption was calculated as follows (Eq. 1)

$\%$ Desorption $=\frac{\text { amount of metal ion desorbed }(\mathrm{mg})}{\text { amount of metal ion adsorbed }(\mathrm{mg})} \times 100$

\subsection{Regeneration and reuse studies}

To evaluate the reusability of the amino- and iminodiacetic acid-type adsorbents, five sequential $\mathrm{Cr}(\mathrm{VI})$ and $\mathrm{Cd}(\mathrm{II})$ adsorption and desorption cycles were performed using the best desorbing solution while following the experimental conditions mentioned above. After each cycle of adsorption-desorption, the adsorbents were washed repeatedly with deionized water until the washings attained neutral $\mathrm{pH}$ and reconditioned for the next adsorption cycle. The solutions after the adsorption and desorption steps were collected, filtered and analyzed with ICP-OES for chromium and cadmium content.

The surface morphologies of the PP-g-PGMA adsorbents before and after the adsorption-desorption cycles were investigated by scanning electron microscopy (SEM) using a Hitachi SU3500 (Hitachi, Japan) microscope at acceleration voltage of $10 \mathrm{kV}$.

\subsection{Kinetics of adsorption and comparison with commercially available ion-exchange resin}

A $0.1 \mathrm{~g}$ adsorbent was immersed in $50 \mathrm{~mL}$ of $10 \mathrm{ppm}$ metal ion solution. The initial $\mathrm{pH}$ values of the $\mathrm{Cr}(\mathrm{VI})$ and $\mathrm{Cd}$ (II) solutions were adjusted to 4.0 and 6.0, respectively, using $0.1 \mathrm{M} \mathrm{NaOH}$ or $0.1 \mathrm{M} \mathrm{HCl}$. About $0.1 \mathrm{~mL}$ aliquots were taken and filtered at specified time intervals. The residual
Fig. 1 Schematic representation for the preparation of grafted GMA on PP and its subsequent functionalization

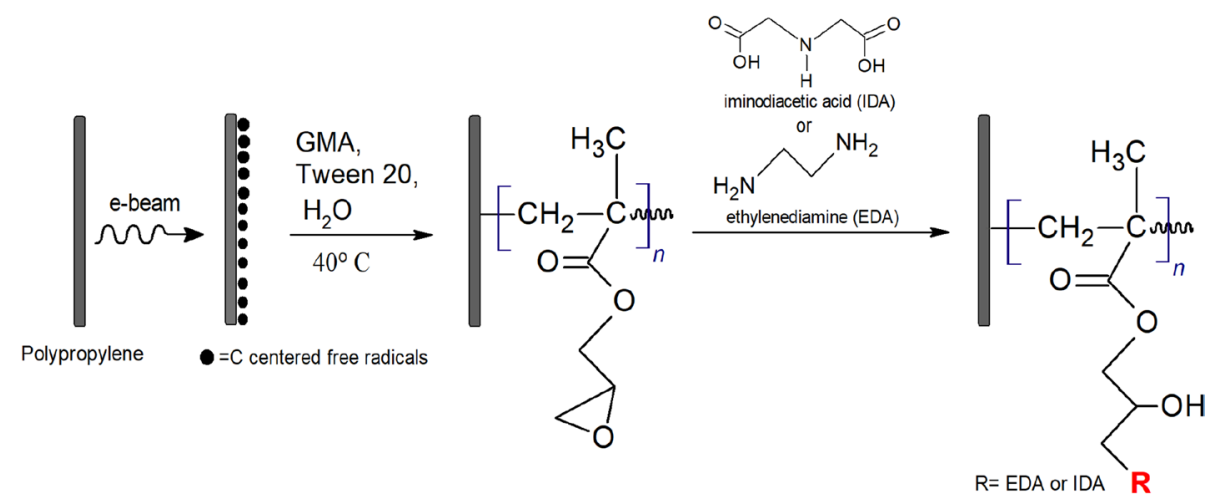

SN Applied Sciences 
metal ion concentration was measured by an Optima 8300 Optical Emission Spectrometer (Perkin Elmer, Japan). The performance of the radiation synthesized adsorbents was compared with Diaion ${ }^{\circledR}$ CR1 1 and CR20 ion exchange resins. These commercially available resins were chosen because they contain chemical groups similar to the synthesized adsorbents, i.e. CR20 contains primary amine groups while CR11 has iminodiacetic acid functional groups.

\subsection{Column adsorption study}

Fixed bed column adsorption of $\mathrm{Cr}(\mathrm{VI})$ or $\mathrm{Cd}(\mathrm{II})$ from a continuously flowing feed solution was carried out using 0.1 $\mathrm{g}$ amino- or iminodiacetic acid- type adsorbent packed in a glass column $(0.7 \mathrm{~cm}$ internal diameter) to yield a $1 \mathrm{~cm}$ adsorbent bed height. Based on the column and adsorbent bed dimensions, the calculated volume of the wet adsorbent bed (bed volume, BV) was approximately $0.385 \mathrm{~cm}^{3}$. This BV value was used as a reference to convert the volume from $\mathrm{mL}$ to $\mathrm{BV}$ of metal ion solutions supplied to the column by dividing the effluent volume with the volume of the adsorbent bed (i.e., $0.385 \mathrm{~cm}^{3}$ ). The adsorbent was equilibrated with water before metal ion adsorption. Feed solution containing $3 \mathrm{ppm}$ of $\mathrm{Cr}(\mathrm{VI})$, with an initial pH of 4 (similar to the $\mathrm{Cr}$ concentration of waste waters from a leather tanning industry in the Philippines) or $\mathrm{Cd}(\mathrm{II})$ at $\mathrm{pH} \mathrm{6,} \mathrm{was} \mathrm{fed} \mathrm{to} \mathrm{the} \mathrm{column} \mathrm{at} \mathrm{different} \mathrm{flow} \mathrm{rates;} 1$ $\mathrm{mL} / \mathrm{min}(156 \mathrm{BV} / \mathrm{h}), 5 \mathrm{~mL} / \mathrm{min}(780 \mathrm{BV} / \mathrm{h})$ and $10 \mathrm{~mL} / \mathrm{min}$ (1560 BV/h). In this work, the breakthrough point was designated as the feed volume supplied to the column up to the BV with effluent concentrations greater than $0.1 \mathrm{ppm}$ and 0.05 ppm, which is the Philippines' effluent standard for $\mathrm{Cr}(\mathrm{VI})$ and $\mathrm{Cd}(\mathrm{II})$ in inland waters, respectively [15]. The column effluent was collected at given time intervals and analyzed for $\mathrm{Cr}$ and $\mathrm{Cd}$ concentration using ICP-OES.

\section{Results and discussions}

Batch adsorption studies of $\mathrm{Cr}(\mathrm{VI})$ and $\mathrm{Cd}(\mathrm{II})$ using functionalized PP-g-PGMA was previously conducted by the authors. It has been shown that the amino-type adsorbent was effective in the removal of $\mathrm{Cr}(\mathrm{VI})$ at $\mathrm{pH} 4$, with a maximum adsorption capacity $\left(\mathrm{q}_{e, \max }\right)$ of $153 \mathrm{mg} / \mathrm{g}$. On the other hand, the iminodiacetic acid-type adsorbent was found to be more efficient in the $\mathrm{Cd}$ (II) adsorption, with a calculated $\mathrm{q}_{e, \max }$ of $57 \mathrm{mg} / \mathrm{g}$ in the $5-6 \mathrm{pH}$ range. It was also established that the adsorption of $\mathrm{Cr}(\mathrm{VI})$ and $\mathrm{Cd}(\mathrm{II})$ could be modelled using the Freundlich and Langmuir isotherm equations, respectively [14]. An ideal adsorbent should not only effectively remove its target metal ion but should also be low in cost, and readily available.
Thus, in the present study, the efficiency and reusability of the synthesized adsorbents were evaluated through sequential adsorption-desorption cycles. A reusable adsorbent is more economical than the single-use ones, and also reduces the production of secondary pollutants. Fixed bed column adsorption studies of the amino- and iminodiacetic acid-type adsorbents were also conducted given the possible bench-scale testing of the adsorbent and subsequent upscaling.

\subsection{Desorption of $\mathrm{Cr}(\mathrm{VI})$ and $\mathrm{Cd}(\mathrm{II})$}

The desorption of heavy metals bound to the adsorbent is essential to maximize the use of the adsorbent, which could lead to lower process cost, thus making its utilization more practical. Desorption experiments were carried out using different desorbing agents to determine the most suitable solution for the treatment of spent adsorbents.

Low molecular weight organic acids (LMWOAs, e.g., acetic, citric, and oxalic acid) are frequently studied for desorption of metal ions existing in their elemental form because LMWOAs possess less environmental risks than inorganic acids. The efficiency of different organic acids in removing the bound $\mathrm{Cd}(\mathrm{II})$ ions is shown in Fig. 2a. All of the tested organic acid solutions were able to strip off more than $90 \%$ of the adsorbed $\mathrm{Cd}$ (II) from the iminodiacetic acid-type adsorbent. The results from the desorption tests using acetic and citric acid were auspicious. The two acids removed almost all the bound $\mathrm{Cd}(\mathrm{II})$ ions, as seen in Fig. 2a. The observed effective desorbing property of the two acids may be attributed to the presence of one or more carboxyl and hydroxyl groups in their structure that could form a soluble complex with heavy metals ions. Also, the effective desorption could be related to their acid dissociation constant (pKa): acetic acid (4.76), citric acid (3.13), oxalic acid (1.25). These numbers indicate that the acids used in desorption provide more free anions for complexing with metals. A large number of free anions, as well as the strong complexing ability of the acids, enhanced the desorption [16-18]. Although the three desorbing solutions showed comparable desorption performance, the succeeding $\mathrm{Cd}$ (II) desorption studies were carried out using citric acid solution because it is generally safer, inexpensive and nonpolluting than acetic and oxalic acid.

Based from the applied conditions, the $\mathrm{Cr}(\mathrm{VI})$ ions at $\mathrm{pH} 4$, existed primarily as oxyanions (e.g., $\mathrm{HCrO}^{-4}$, and $\mathrm{Cr}_{2} \mathrm{O}_{7}^{-2}$ ) in the solution during the adsorption process [19]. Since chromium exists in anionic form, it can be eluted by using bases like $\mathrm{NaOH}$ or $\mathrm{NH}_{4} \mathrm{OAc}$. The use of $\mathrm{NaOH}$ solutions with relatively higher concentrations, i.e., $1.5 \mathrm{M}$ and $2 \mathrm{M}$, gave the highest percent desorption among the solutions tested, removing $\sim 80 \%$ of the bound $\mathrm{Cr}(\mathrm{VI})$ ions from the amino-type adsorbent 


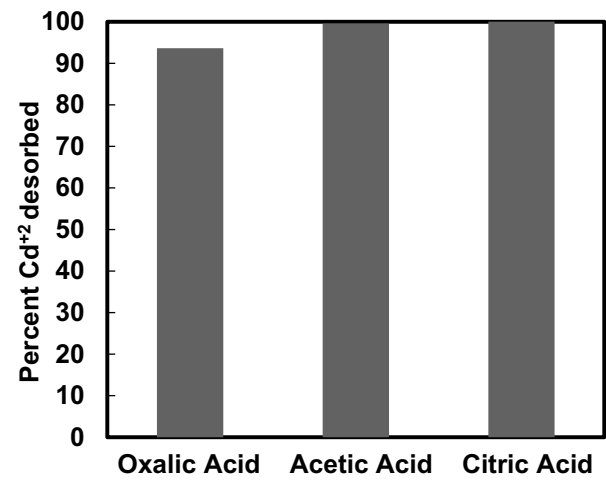

(a)

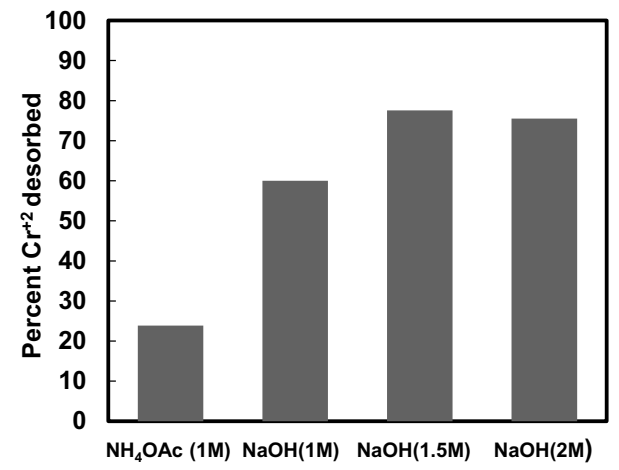

(b)

Fig. 2 Amount of $\mathrm{Cd}(\mathrm{II})$ and $\mathrm{Cr}(\mathrm{VI})$ desorbed expressed as percentage desorption, from the iminodiacetic and amino adsorbent using different desorbing agents

(Fig. 2b). The observed difference in the desorption performance between the acetate and hydroxide ions could be due to the hydrolysis of the acetate ion in the solution, which effectively decreases its concentration in the solution. Complete desorption was not achieved probably because of the high affinity of the oxyanion forms of $\mathrm{Cr}(\mathrm{VI})$ ions to the amine functional groups in the adsorbent.

\subsection{Adsorbent regeneration and reusability}

The possible regeneration of a spent adsorbent plays a significant role in terms of economic and environmental point of views in practical applications. Therefore, in this study, five cycles of adsorption-desorption were performed to evaluate the reusability of the synthesized adsorbent. Herein, $2 \mathrm{M} \mathrm{NaOH}$ and $0.1 \mathrm{M}$ citric acid were used to desorb $\mathrm{Cr}(\mathrm{VI})$ and $\mathrm{Cd}(\mathrm{II})$. Presented in Fig. 3 are the results of successive adsorption-desorption cycles. The adsorption of $\mathrm{Cd}$ (II) towards iminodiacetic type adsorbent was notable. As seen, the adsorbent maintained efficient adsorption $(5 \mathrm{mg} \mathrm{Cd}(\mathrm{II}) / \mathrm{g}$ ) even after five cycles. The stable citrate- Cd(II) complex was due to a large amount of free anions of citric acid ( $\mathrm{pKa}=3.13$ ) that can form complex with $\mathrm{Cd}(\mathrm{II})$ thus, promoting complete removal after five adsorption-desorption cycles [16].

On the other hand, from the initial $97 \%$ adsorption, only $3 \%$ reduction in the performance of amino adsorbent for the removal of $\mathrm{Cr}(\mathrm{VI})$ was observed after the fifth cycle. The slight decrease in adsorption efficiency may be attributed to the oxidized portion of the amino functional groups during the desorption process [20] and because of the incomplete desorption of some strongly bound $\mathrm{Cr}(\mathrm{VI})$ ions. Nonetheless, in the succeeding runs, the adsorbent was still able to remove more than $90 \%$ (3.0 $\mathrm{mg} \mathrm{Cr}(\mathrm{VI}) / \mathrm{g}$ ) of the $\mathrm{Cr}$ ions from the 10-ppm solution. Similar studies were conducted by many authors [21-23] showing $\mathrm{NaOH}$ as a good desorbing solution for hexavalent chromium. The regeneration ability of the synthesized adsorbent was promising because of the strong affinity of chromium to the amine group and the $\mathrm{OH}^{-}$interacting with the chromate ions in the adsorbent causing the removal of chromium during desorption. The results of the regeneration and reuse studies suggest that that the adsorption was reversible and the synthesized adsorbents can be reused at least five times.

Figures 4 and 5 a showed that prior adsorption, amino and iminodiacetic type adsorbent has smooth and even
Fig. 3 Plots of successive adsorption-desorption cycles of Cd(II) using iminodiacetic adsorbent (left) and $\mathrm{Cr}(\mathrm{VI})$ using amino adsorbent (right)
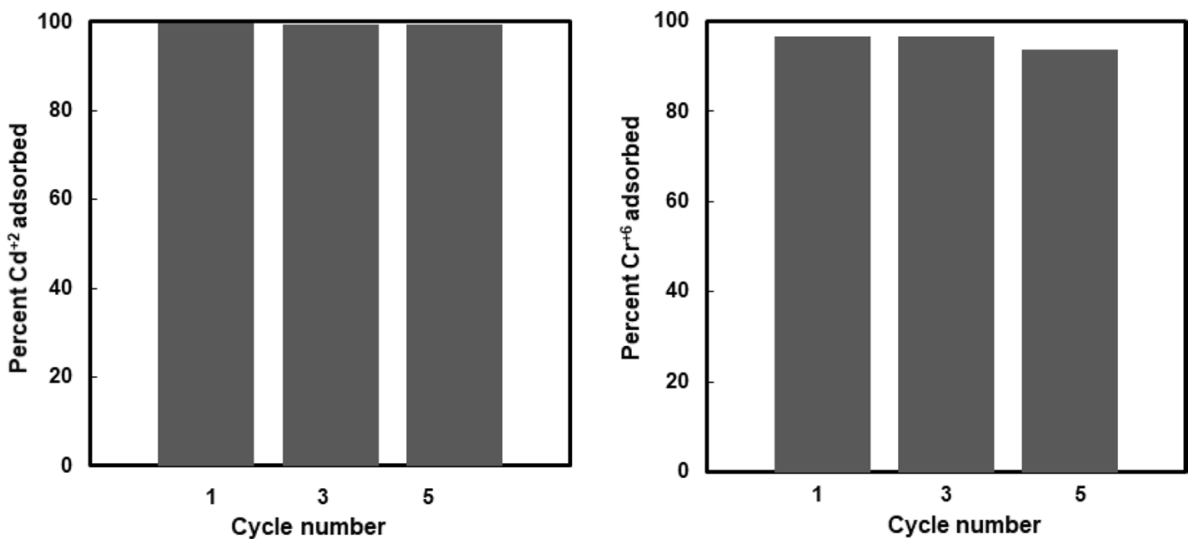

SN Applied Sciences A SPRINGER NATURE journal 

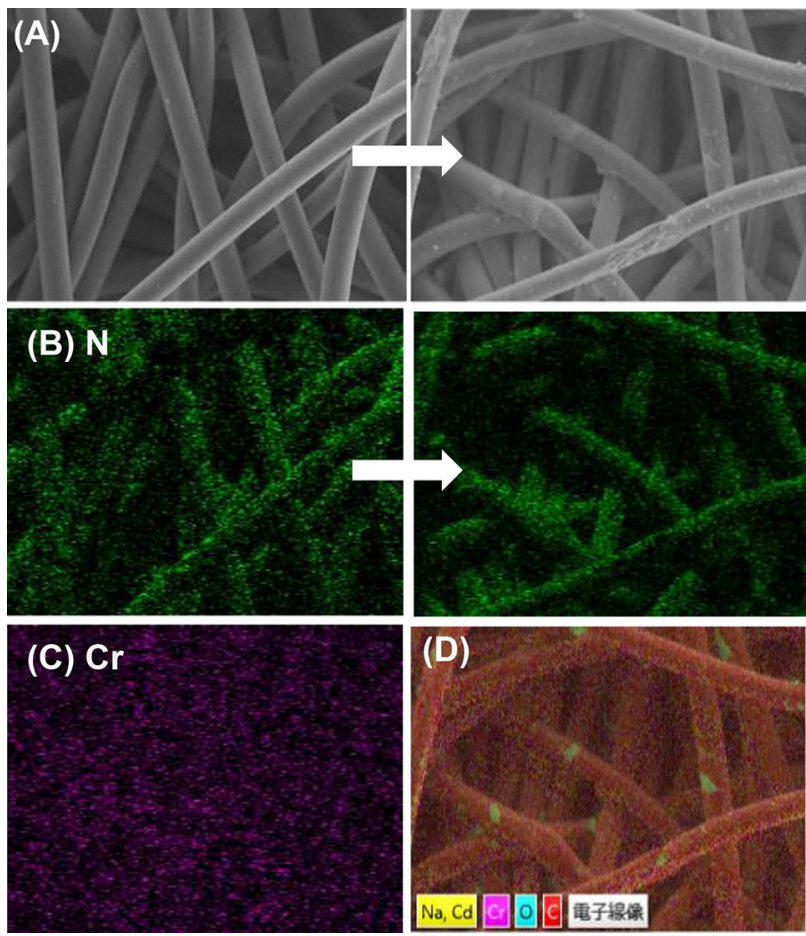

(D)

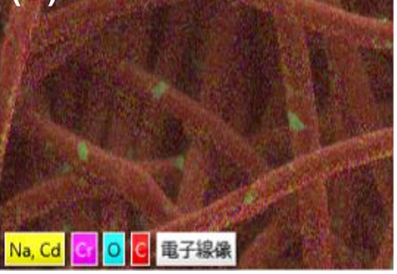

Fig. 4 SEM image of (a) amino adsorbent before and after adsorption-desorption cycle and EDX maps of (b) $\mathrm{N}$ element (c) $\mathrm{Cr}$ element (d) amino adsorbent after five adsorption-desorption cycles

surface. After five cycles of $\mathrm{Cr}(\mathrm{VI})$ and $\mathrm{Cd}(\mathrm{II})$ adsorption and regeneration using $\mathrm{NaOH}$ or citric acid, the surface appeared to become uneven and slightly porous which might indicate that the metal ions has been effectively adsorbed and desorbed onto these areas. More importantly, no remarkable damage has observed to the adsorbent indicating that the use of oxidative base or the weak acid did not have a significant effect on the fiber morphology. This conclusion was also supported by the result of EDX mapping in Figs. 4 and 5b. As seen, the distribution of nitrogen representing the ethylenediamine and iminodiacetic acid group is quite homogenous after regeneration cycles. This means that the active sites for adsorption were still intact, thus, it can still be used for another adsorption cycle. Furthermore, maps of $\mathrm{Cr}$ and $\mathrm{Cd}$ (Figs. 4 and 5d) shows that most of the heavy metals were removed and successful regeneration was achieved. These results confirmed that the synthesized adsorbent has good recycling ability and is useful for wastewater treatment.

\subsection{Kinetics of adsorption/comparison with commercial resin}

The effect of contact describes the adsorbent uptake rate between the adsorbent and heavy metal, which defines the efficiency of adsorption. In this study, kinetics of
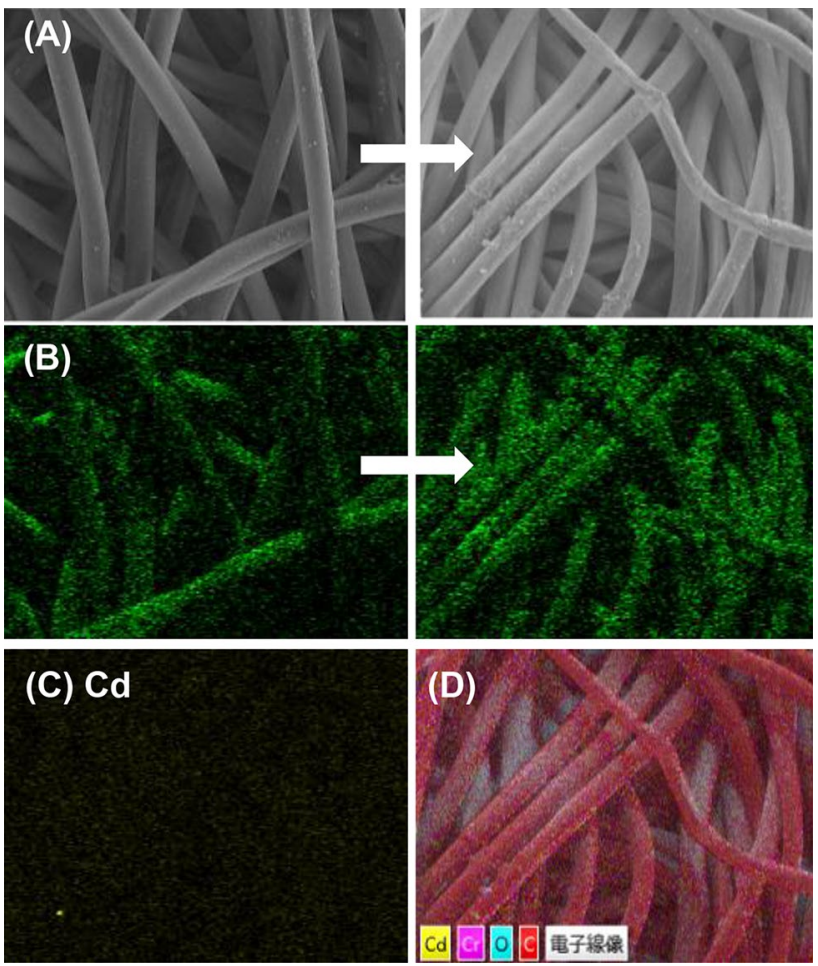

Fig. 5 SEM image of (a) iminodiacetic adsorbent before and after adsorption-desorption cycle and EDX maps of (b) $\mathrm{N}$ element before (c) Cd element (d) iminodiacetic adsorbent after five adsorption-desorption cycles

adsorption was carried out by measuring the rate adsorption as a function of time. Two simplified kinetic models, pseudo-first and pseudo- second-order, were used to fit the experimental data. The pseudo-first-order kinetic model is represented by Eq. 2 .

$\log \left(q_{e}-q_{t}\right)=\log \left(q_{e}\right)-\frac{k_{1}}{2.303} t$

where $k_{1}$ is the pseudo- first-order rate adsorption constant $\left(\mathrm{min}^{-1}\right), \mathrm{q}_{e}$ and $\mathrm{q}_{t}(\mathrm{mg} / \mathrm{g})$ are the amounts of metal ion adsorbed at equilibrium and time $t(\mathrm{~min})$, respectively. The values of $\mathrm{q}_{e}$ and $\mathrm{k}_{1}$ were calculated from the intercept and slope of $\ln \left(q_{e}-q_{t}\right)$ plotted against time $t$. First order kinetics is based on the assumption that rate is directly proportional to the number of free sites. On the other hand, the pseudo-second-order equation where the rate of adsorption is proportional by the square number of unoccupied sites is expressed as Eq. 3.

$\frac{t}{q}=\frac{1}{k_{2} q_{e}^{2}}+\frac{t}{q_{e}}$

where $k_{2}$ is the pseudo-second-order equilibrium rate constant $(\mathrm{g} / \mathrm{mg} \cdot \mathrm{min})$ which can be calculated by plotting $t / \mathrm{q}_{t}$ vs $t$. The validity of each models is determined based on

\section{SN Applied Sciences}


Table 1 Kinetic parameters for the adsorption of $\mathrm{Cr}$ and $\mathrm{Cd}$ using amino and iminodiacetic-type adsorbent

\begin{tabular}{lll}
\hline Kinetic model & $\mathrm{Cr}$ & $\mathrm{Cd}$ \\
\hline Pseudo first order & & \\
$k_{1}$ & 0.0672 & 0.1437 \\
$r^{2}$ & 0.9681 & 0.9949 \\
Pseudo second order & & \\
$k_{2}$ & 0.0548 & 0.3101 \\
$r^{2}$ & 0.9995 & 1.00 \\
\hline
\end{tabular}

the value of the correlation coefficient $\left(\mathrm{r}^{2}\right)$ obtained which is higher for the pseudo-second-order (Table 1).

It can be concluded that the adsorption of $\mathrm{Cr}$ and $\mathrm{Cd}$ using amino and iminodiacetic-type adsorbent obeys second order kinetic model. This model assumed that the rate determining step of the adsorption process involves chemisorption through physicochemical interactions between the sorbate and sorbent [24-26]. Thus, it is possible that the metal ions are chelated by the amino or the iminodiacetic acid ligands on the radiation-grafted adsorbents.

The effect of contact time on the removal of Cd(II) and $\mathrm{Cr}(\mathrm{VI})$ ions by the radiation-grafted adsorbent and commercially available resins is also shown in Fig. 6. After 10 min contact time, the iminodiacetic adsorbent removed $>80 \%$ of the $\mathrm{Cd}(\mathrm{II})$ ions in the solution. This was higher by $10 \%$ than the amount adsorbed by the CR11 resin (Fig. 6a). For $\mathrm{Cr}(\mathrm{VI})$ adsorption, the amino adsorbent removed $>95 \%$ of the $\mathrm{Cr}(\mathrm{VI})$ ions after 45 min contact time, while the commercial resin removed only about $80 \%$ of the $\mathrm{Cr}(\mathrm{VI})$ ions during the same period (Fig. $6 \mathrm{~b}$ ).

This advantage could be attributed to the high effective surface area of the fibrous adsorbent like PP NWF wherein the fiber diameters are several times smaller than those of spherical resin adsorbents thus the high diffusion rate of the metal ions which could lead to high adsorption capacity [6]. The synthesized adsorbents described in this work performed on par with, if not better than the commercial resins. Nonetheless, both radiation-grafted adsorbents and commercially available resins were able to remove most of the dissolved metal ions in the solution given sufficient contact time.

\subsection{Column adsorption study}

Continuous removal of $\mathrm{Cr}(\mathrm{VI})$ and $\mathrm{Cd}(\mathrm{II})$ using a column with an inner diameter of $0.7 \mathrm{~cm}$ and flow rates of $1,5,10$ $\mathrm{mL} / \mathrm{min}$ was studied. Fig. 7 shows the plot of relative effluent concentration against volume of solution that passed through the column, expressed in bed volumes (BV).

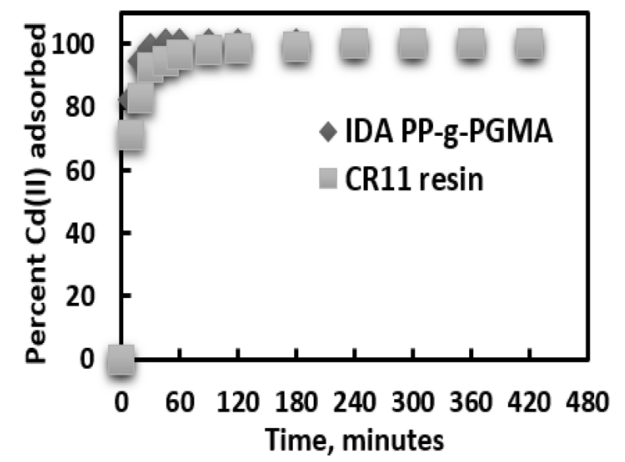

(a)

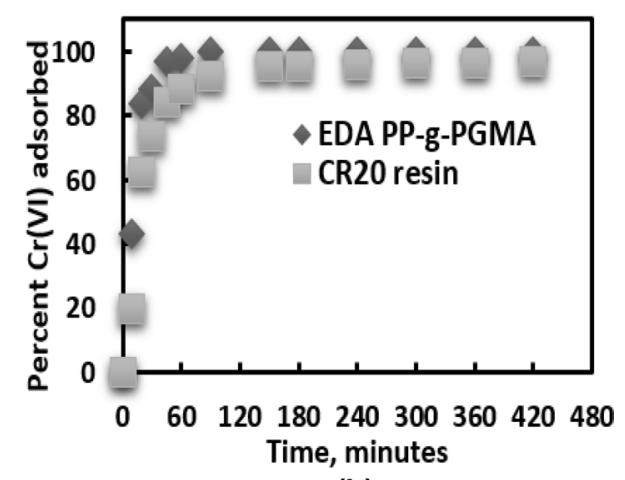

(b)

Fig. 6 Relative amounts of (a) $\mathrm{Cd}(\mathrm{II})$ and (b) $\mathrm{Cr}(\mathrm{VI})$ ions removed by IDA and EDA modified PP-g-PGMA and commercial resins from 10 ppm solutions as a function of time

Breakthrough $\left(C_{t} / C_{o}=0.033\right)$ was achieved after 4000 BV (i.e. $>1500 \mathrm{~mL}$ solution) of $\mathrm{Cr}(\mathrm{VI})$ solution passed through the column-packed adsorbent (Fig. 7a) at a rate of $1 \mathrm{~mL} / \mathrm{min}\left(155 \mathrm{BV} \mathrm{h}^{-1}\right)$. After the breakthrough was reached, the effluent $\mathrm{Cr}(\mathrm{VI})$ content increased gradually to concentrations higher than the $0.1 \mathrm{ppm}$, which is the regulatory limit set by Philippines' Department of Environment and Natural Resource (DENR) for Class C inland waters. The adsorbent used in this column adsorption study weighted $0.1 \mathrm{~g}$ and a bed volume of $0.385 \mathrm{~cm}^{3}$ but was able to treat more than $1500 \mathrm{~mL}$ of $3 \mathrm{ppm} \mathrm{Cr}(\mathrm{VI})$ solution before the breakthrough.

The performance of the amino adsorbent-packed column was also tested at higher flow rates of $780 \mathrm{BV} \mathrm{h}^{-1}$ and $1560 \mathrm{BV} \mathrm{h}^{-1}$. In both cases, the breakthrough was not reached after $1200 \mathrm{BV}$ of $\mathrm{Cr}(\mathrm{VI})$ solution was fed into the column, as shown in Fig. 7b. Early elution of $\mathrm{Cr}(\mathrm{VI})$ ions was also observed. However, after a few volumes of the solution passed through the adsorbent, the effluent concentration became $<0.05 \mathrm{ppm}$. Similarly, column adsorption of $\mathrm{Cd}$ (II) using iminodiacetic adsorbent also demonstrated promising results after passing of 1300 BV (i.e. $500 \mathrm{~mL}$ ) of $3 \mathrm{ppm} \mathrm{Cd(II)} \mathrm{solution} \mathrm{also} \mathrm{at} \mathrm{different}$ flow rates (Fig. 8). 


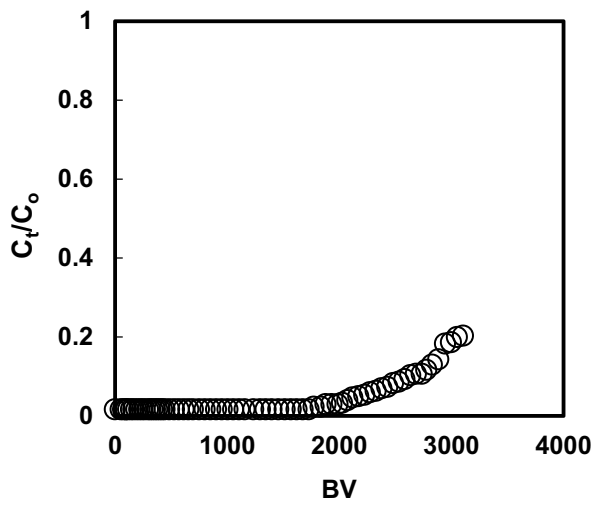

(a)

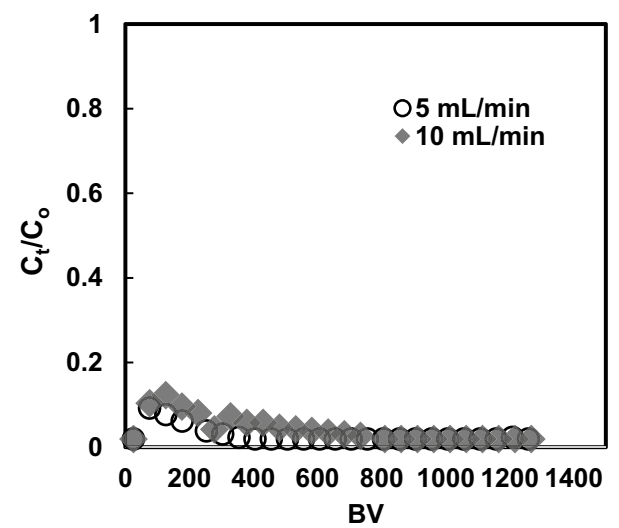

(b)

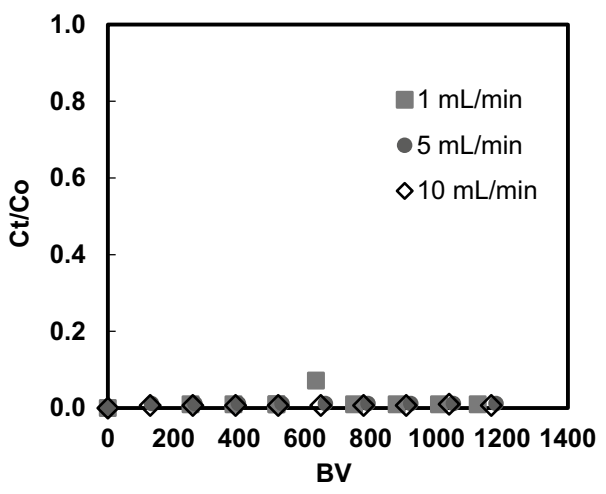

Fig. 8 Breakthrough profile of $\mathrm{Cd}(\mathrm{II})$ adsorption from feed solution containing $3 \mathrm{ppm} \mathrm{Cd}(\mathrm{II})$ at $\mathrm{pH} 6$ under a feed flow rate of $1 \mathrm{~mL}$

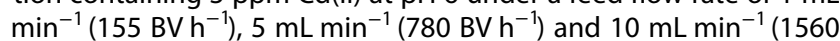
$\mathrm{BVh}^{-1}$ )

of varying flow rates during adsorption. Flow rate is an important parameter because it affects the residence time that the adsorbate is in contact with the adsorbent which will then affect the breakthrough and total adsorption capacity [30, 31].

In this study, the lowest flow rate used was $155 \mathrm{BVh}^{-1}$, higher than typical effective flow rates of commercial granular resin adsorbents which is $5-50 \mathrm{BVh}^{-1}[32,33]$. The notable performance of the synthesized adsorbents may be attributed to two factors: a) the high affinity of $\mathrm{Cr}(\mathrm{VI})$ and $\mathrm{Cd}(\mathrm{II})$ ions to the amino or iminodiacetic groups that were imparted after radiation-induced graft polymerization and functionalization of the PP fibers; and $b$ ) the high surface area of the adsorbent due to its fibrous nature.

Several column adsorption studies were already performed using fibrous adsorbent, synthesized using radiation-induced graft polymerization showing extremely high performance in the adsorption of $\mathrm{Hg}, \mathrm{Cs}$ and $\mathrm{As}[6,34,35]$. Based on the data presented above, the synthesized amino and iminodiacetic-type adsorbent shows good adsorption capacity and proved to have a potential in the removal of chromium and cadmium in wastewater treatment.

\section{Conclusion}

The amino and iminodiacetic adsorbent was successfully synthesized using electron beam induced grafting of GMA on PP followed by modification using EDA and IDA. Metal loaded adsorbents were prepared by adsorption of $\mathrm{Cr}(\mathrm{VI})$ and $\mathrm{Cd}(\mathrm{II})$ to evaluate its desorption profile, reusability, and column performance. The $\mathrm{Cd}$ (II) ions bound on the IDA functionalized PP-g-PGMA were fully desorbed by organic acids while $2 \mathrm{M} \mathrm{NaOH}$ was found to be effective in removing bound $\mathrm{Cr}(\mathrm{VI})$ ions from the EDA functionalized PP-g-PGMA. The radiation-grafted adsorbents can be 
regenerated, maintaining $>90 \%$ adsorption efficiency even after five cycles.

Furthermore, the synthesized adsorbents followed pseudo-second order kinetics and shown to have comparable adsorption performance with commercially available iminodiacetic and amino type ion exchange resins. The column-packed EDA functionalized PP-g-PGMA adsorbent can be used to treat more than $4000 \mathrm{BV}(>1500 \mathrm{~mL})$ of a solution containing $3 \mathrm{ppm} \mathrm{Cr}(\mathrm{VI})$ at a rate of $155 \mathrm{BV} \mathrm{h}^{-1}$. Upon increasing flow rate, the breakthrough was not yet attained after $1300 \mathrm{BV}$ of solution passed through the column. IDA functionalized PP-g-PGMA exhibited the same performance for $\mathrm{Cd}$ adsorption using the same conditions. Additionally, results on continuous adsorption of amino adsorbent showed 25\% decrease of $\mathrm{Cr}(\mathrm{VI})$ using 1900 $\mathrm{BV}$ of actual tannery wastewater. Based on these results, the synthesized amino and iminodiacetic adsorbents are potentially useful material for the removal of heavy metals in industrial wastewater facilities.

Acknowledgements This study is part of the project "Radiationinduced grafting of nonwoven fabrics for tanning industry wastewater treatment to meet Class C effluent heavy metal standard" which was funded by the Philippine Council for Industry, Energy and Emerging Technology Research and Development (PCIEERD), DOST.

\section{Compliance with ethical standards}

Conflict of interest The authors declare that they have no conflict of interest.

\section{References}

1. Cervera ML, Arnal MC, De La Guardia M (2003) Removal of heavy metals by using adsorption on alumina or chitosan. Anal Bioanal Chem 375:820-825. https://doi.org/10.1007/s00216-003-1796

2. Afkhami A, Madrakian T, Karimi A, Amini A (2007) Effect of treatment of carbon cloth with sodium hydroxide solution on its adsorption capacity for the adsorption of some cations. Colloids Surf A 304:36-40. https://doi.org/10.1016/j.colsurfa.2007.04.029

3. Narin I, Soylak M, Elçi L, Doğanc M (2000) Determination of trace metal ions by AAS in natural water samples after preconcentration of pyrocatechol violet complexes on activated carbon column. Talanta 52:1041-1046. https://doi.org/10.1016/S0039 -9140(00)00468-9

4. Zhaohui $L$ (1998) Chromate extraction from surfactant-modified zeolite surfaces. J Environ Qual 27:240-242. https://doi. org/10.2134/jeq1998.00472425002700010034x

5. Nwabanne JT, Igbokwe PK (2012) Adsorption performance of packed bed column for the removal of lead(II) using oil palm fibre. Int J Appl Sci Technol 2:106-115

6. Sekine A, Seko N, Tamada M, Suzuki Y (2010) Biodegradable metal adsorbent synthesized by graft polymerization onto nonwoven cotton fabric. Radiat Phys Chem 79:16-21. https:// doi.org/10.1016/j.radphyschem.2009.08.007

7. Pickering KL, Aruan Efendy MG, Le TM (2016) A review of recent developments in natural fibre composites and their mechanical performance. Compos Part A Appl S 83:98-112. https://doi. org/10.1016/j.compositesa.2015.08.038

8. Jyo A, Aoki S, Kishita T, Yamabe K, Tamada M, Sugo T (2001) Phosphonic acid fiber for selective and extremely rapid elimination of Lead(II). Anal Sci 17:i201-i204. https://doi.org/10.14891/anals cisp.17icas.0.i201.0

9. Ting TM, Nasef MM (2017) Modification of polyethylene-polpropylene fibers by emulsion and solvent radiation grafting systems for boron removal. Fiber Polym 18:1048-1055. https:// doi.org/10.1007/s12221-017-6840-5

10. Elwakeel $\mathrm{KZ}$ (2010) Removal of $\mathrm{Cr}(\mathrm{VI})$ from alkaline aqueous solutions using chemically modified magnetic chitosan resins. Desalination 250:105-112. https://doi.org/10.1016/j.desal .2009.02.063

11. Kavaklı PA, Kavaklı C, Güven O (2014) Preparation and characterization of $\mathrm{Fe}$ (III)-loaded iminodiacetic acid modified GMA grafted nonwoven fabric adsorbent for anion adsorption. Radiat Phys Chem 94:105-110. https://doi.org/10.1016/j.radphysche m.2013.07.003

12. Barsbay M, Kavaklı PA, Tilki S, Kavaklı C, Güven O (2018) Porous cellulosic adsorbent for the removal of $\mathrm{Cd}(\mathrm{II}), \mathrm{Pb}$ (II) and $\mathrm{Cu}(\mathrm{II})$ ions from aqueous media. Radiat Phys Chem 142:70-76. https ://doi.org/10.1016/j.radphyschem.2017.03.037

13. Pang L, Hu J, Zhang M, Yang C, Wu G (2018) An efficient and reusable quaternary ammonium fabric adsorbent prepared by radiation grafting for removal of $\mathrm{Cr}(\mathrm{VI})$ from wastewater. Environ Sci Pollut Res Int 25:11045. https://doi.org/10.1007/s1135 6-018-1355-1

14. Madrid JF, Lopez GE, Abad LV (2017) Application of full-factorial design in the synthesis of polypropylene-g-poly (glycidyl methacrylate) functional material for metal ion adsorption. Radiat Phys Chem 136:64-63. https://doi.org/10.1016/j.radphysche m.2017.01.047

15. Department of Environment and Natural Resources (1991) DENR administrative order 35- revised effluent regulations of 1990. Revising and amending the effluent regulations of 1982. http://119.92.161.2/embgovph/Portals/0/Cache/DAO\%20199 0-35.pdf. Accessed 3 March 2017

16. Qin F, Shan X, Wei B (2004) Effects of low-molecular-weight organic acids and residence time on desorption of $\mathrm{Cu}, \mathrm{Cd}$, and $\mathrm{Pb}$ from soils. Chemosphere 57:253-263. https://doi. org/10.1016/j.chemosphere.2004.06.010

17. Gao Y, He J, Ling W, Hu H, Liu F (2003) Effects of organic acids on copper and cadmium desorption from contaminated soils. Environ Int 29(5):613-618. https://doi.org/10.1016/S0160 -4120(03)00048-5

18. Yang JY, Yang XE, He ZL, Li TQ, Shentu JL, Stoffella PJ (2006) Effects of $\mathrm{pH}$, organic acids, and inorganic ions on lead desorption from soils. Environ Pollut 143:9-15. https://doi. org/10.1016/j.envpol.2005.11.010

19. Wang J, Zhao L, Duan W, Han L, Chen Y (2012) Adsorption of aqueous $\mathrm{Cr}(\mathrm{VI})$ by novel fibrous adsorbent with amino and quaternary ammonium groups. Ind Eng Chem Res 51:13655-13662. https://doi.org/10.1021/ie3013874

20. Gao Q, Hua J et al (2017) Radiation-induced graft polymerization for the preparation of a highly efficient UHMWPE fibrous adsorbent for $\mathrm{Cr}(\mathrm{VI})$ removal. Radiat Phys Chem 130:92-102. https:// doi.org/10.1016/j.radphyschem.2016.08.004

21. Alfa-Sika MS, Liu F, Chen H (2010) Optimization of key parameters for Chromium(VI) removal from aqueous solutions using activated charcoal. J Soil Sci Environ Manage 1:55-62

22. Gorzin F, Ghoreyshi AA (2013) Synthesis of a new low-cost activated carbon from activated sludge for the removal of $\mathrm{Cr}(\mathrm{VI})$ from aqueous solution: equilibrium, kinetics, thermodynamics and desorption studies. Korean J Chem Eng 30:1594-1602. https ://doi.org/10.1007/s11814-013-0079-7 
23. Mishra SP (2014) Adsorption-desorption of heavy metal ions (Review). Curr Sci 107:601-612

24. Simonin JP (2016) On the comparison of pseudo-first order and pseudo-second order rate laws in the modeling of adsorption kinetics. Mater 300:254-263. https://doi.org/10.1016/j. cej.2016.04.079

25. Monier M, Ayad DM, Sarhan AA (2010) Adsorption of Cu(II), $\mathrm{Hg}(\mathrm{II})$, and $\mathrm{Ni}(\mathrm{II})$ ions by modified natural wool chelating fibers. J Hazard Mater 176:348-355. https://doi.org/10.1016/j.jhazm at.2009.11.034

26. Ho YS, McKay G (1999) Pseudo-second order model for sorption processes. Process Biochem 34:451-465. https://doi. org/10.1016/S0032-9592(98)00112-5

27. Franus M, Bandura L (2014) Sorption of heavy metal ions from aqueous solution by glauconite. Fresenius Environ Bull 23:825-839

28. Oyetade OA, Nyamori VO, Martincigh BS, Jonnalagadda SB (2016) Nitrogen functionalized carbon nanotubes as a novel adsorbent for the removal of $\mathrm{Cu}$ (II) from aqueous solution. RSC Adv 6:2731-2745. https://doi.org/10.1039/C5RA23900A

29. Ojemaye M, Okoh O, Okoh A (2018) Uptake of Zn2+ and As3+ from wastewater by adsorption onto imine functionalized magnetic nanoparticles. Water 10:36. https://doi.org/10.3390/w1001 0036

30. Awual MR, Shenashen MA, Jyo A, Shiwaku H, Yaita T (2014) Preparing of novel fibrous ligand exchange adsorbent for rapid column-mode trace phosphate removal from water. Ind Eng Chem Res 20:2480-2487. https://doi.org/10.1016/j.jiec.2013.11.016
31. Genc-Fuhrman H, Bregnhoj H, McConchie D (2005) Arsenate removal from water using sand-red mud columns. Water Res 39:2944-2954. https://doi.org/10.1016/j.watres.2005.04.050

32. Suzuki TM, Bomani JO, Matsunaga H, Yokoyama T (2000) Preparation of porous resin loaded with crystalline hydrous zirconium oxide and its application to the removal of arsenic. React Funct Polym 43:165-172. https://doi.org/10.1016/S1381 -5148(99)00038-3

33. Sahu SK, Meshram P, Pandey BB, Kumar V, Mankhand TR (2009) Removal of chromium(III) by cation exchange resin, Indion 790 for tannery waste treatment. Hydrometallurgy 99:170-174. https://doi.org/10.1016/j.hydromet.2009.08.002

34. Shibata T, Seko N, Amada H, Kasai N, Saiki S, Hoshina H, Ueki Y (2015) Development of an adsorbent for Cs removal synthesized by radiation induced graft polymerization. J Ion Exch 26:9-14. https://doi.org/10.5182/jaie.26.9

35. Hoshina H, Takahashi M, Kasai N, Seko N (2012) Adsorbent for Arsenic $(V)$ removal synthesized by radiation-induced graft polymerization onto nonwoven cotton fabric. Int J Org Chem 2:173-177. https://doi.org/10.4236/ijoc.2012.23026

Publisher's Note Springer Nature remains neutral with regard to jurisdictional claims in published maps and institutional affiliations. 